\title{
原著＼cjkstart雀豚・捻鍼による鍼鎮痛過程に関する末梢機序
}

\author{
橋 本 辰 幸* 相川 貞
}

要旨手技運鍼による鍼鎮痛末梢機序を検討するためにラット脊髄 侵害受容ニューロン誘発発火を指標とし，1）皮膚への侵害的ピンチ 刺激と銊刺激の比較，2）経穴部の皮膚·皮膚と筋肉・筋肉への選択的 鍼刺激，3）経穴部への高張食塩水筋注と鍼刺激との比較をそれぞれ おこなった。皮膚のピンチ刺激についてはその抑制時間・抑制強度に おいて鍼刺激と同様の結果を得た。また鍼刺激部位が皮膚よりも筋肉 にまで及ぶと銊鎮痛効果を発現した。また高張食塩水筋注でも類似の 効果が観察された。以上の結果から雀豚・捻鍼により惹起される鎮痛 効果は, 深部のポリモーダル受容器が梁く関与した内因性痛覚抑制系 の賦活によることが示唆された。

\section{Manual acupuncture and its peripheral mechanisms: involvement of nociceptors in muscle.}

\author{
Tatsuyuki Hashimoto and Sadao Aikawa \\ Department of Physiology, School of Hygienic Sciences, Kitasato University \\ (The Japan Society of Acupuncture, Kanagawa branch)
}

\begin{abstract}
Peripheral mechanisms that induce analgesic effects in manual acupuncture were studied in urethane-anesthetized rats. Unitary extracellular recordings were made from spinal wide dynamic range (WDR) neurons and repetitive electrical stimuli were delivered to the excitatory receptive fields to determine a noxious index. First, the analgesic effects of manual acupuncture and a noxious pinch to the skin (Diffuse Noxious Inhibitory Controls: DNIC) were compared. Second, manual acupuncture was applied to different structures at the acupuncture point, such as the skin, skin plus muscle, and muscle. In a third experiment, the analgesic effects of intramuscular injection
\end{abstract}

Key words: Manual acupuncture, DNIC, Hypertonic NaCl, Peripheral mechanism, Polymodal receptor

* Tatsuyuki HASHIMOTO 北里大学 衛生学部 生理学教室 (全日本鍼炎学会 神奈川地方会)

共同研究者: Sadao AIKAWA 北里大学 衛生学部 生理学教室 (全日本鍼炎学会 神奈川地方会)

Key Words : 雀啄・捻鍼, DNIC, 高張食塩水, 末梢機序, ポリモーダル受容器 
of $4.5 \% \mathrm{NaCl}$ and manual acupuncuture were compared. Manual acupuncture and a noxious pinch exhibited a very similar time course and magnitude of inhibitory effects on C-evoked discharges. As for differential stimulation of the acupuncture point, application of the needle to the skin only was less effective than to the skin plus muscle or the muscle only. Both intramuscular injection of $4.5 \%$ $\mathrm{NaCl}$ and manual acupuncture reduced $\mathrm{C}$-evoked discharges while injection of isotonic saline produced almost no inhibitory effects. These data suggest that application of manual acupuncture might arouse noxious sensations that result in activating pain inhibitory processes. Moreover, it is thought that excitation of polymodal receptors in the muscle is a critical factor in inducing analgesic effects in manual acupuncture.

\section{Introduction}

Numerous studies have been conducted on acupuncture analgesia and a growing body of evidence has accumulated concerning its underlying mechanisms, especially with regard to central analgesic processes $^{1 \sim 3)}$. The majority of these studies have used electroacupuncture (EA) to apply acupuncture

stimulation $^{4 \sim 6)}$. However, acupuncture traditionally refers to the procedure of inserting fine needles into particular points on the body and manually manipulating these needles to produce the desired effects.

Very few animal studies have focused on manual acupuncture. Bing et al. ${ }^{7}$ reported that manual acupuncture produced long-lasting inhibitory effects on C-evoked discharges from convergent neurons in the trigeminal nucleus caudalis. Hashimoto et al. $^{8)}$ demonstrated similar long-lasting inhibitory effects as well as short-term inhibition of C-evoked discharges in spinal WDR neurons.

Accordingly, the peripheral mechanisms of manual acupuncture have been poorly discussed while several types of afferent fibers activated by EA have been proposed ${ }^{9,10}$. Recent studies have provided evidence that polymodal receptors play an important role in producing acupuncture effects and functional relationships to the acupuncture point have been suggested ${ }^{11,12}$.

In order to investigate possible peripheral factors involved in manual acupuncture, three different experiments were carrid out. The first compared the analgesic effect of manual acupuncture with that of a noxious pinch to the skin (DNIC). The second used selective stimulation by manual acupuncture of different structures at the acupuncture point such as the skin only, skin plus muscle, and muscle only. The third experiment compared the efficacy of manual acupuncture with that of intramuscular injection of hypertonic $\mathrm{NaCl}$ into the acupuncture point.

\section{Methods}

\section{Animal preparation}

Twenty four male Wistar rats $(230-350 \mathrm{~g})$ were anesthetized with urethane (1.4g/ $\mathrm{kg}$ i.p. initially) and injected with atropine $(0.1 \mathrm{mg}$ s.c.) to reduce tracheal secretions. Cannulae were inserted into the trachea, a common carotid artery and an external jugular vein. Arterial blood pressure and rectal temperature were continuously monitored and maintained within normal physiological limits. The animal was placed in a rat stereotaxic frame and the lumbar spinal cord was exposed by laminectomy (L5) and covered by pools of warm paraffin oil.

The rats were immobilized with an i.v. infusion of pancuronium bromide $(0.2 \mathrm{mg} / \mathrm{kg}$ for induction, $0.1 \mathrm{mg} / \mathrm{kg} / \mathrm{hr}$ for maintenance) and ventilated artificially. The level of anesthesia was determined 
by examination of pupillary size and blood pressure changes during noxious stimulation. If autonomic reflex activity was detected, an additional dose of urethane (0.1-0.2g/ $\mathrm{kg}$ i.v.) was immediately infused.

\section{Recording and stimulation of the receptive field}

Extracellular recordings were made from lumbar dorsal horn neurons with glass micropipettes filled with a mixture of $2 \%$ sodium acetate and pontamine sky blue (impedance: $5-10 \mathrm{M} \Omega$ ) (Fig. 1A). As the microelectrode was positioned in the spinal cord, neurons were tested for responsiveness to cutaneous mechanical stimulation such as brushing, stroking, moderate pressure and pinching. The present study concentrated on WDR neurons. Nociceptive-specific neurons were not considered in the present study due to the high potential for traumatic damage to the receptive field by repetitive pinching stimuli while exploring the field. Low-threshold mechanoreceptive neurons were also excluded because this study focused on the analgesic effects on nociceptive inputs into the spinal cord. Recordings were amplified and continuously monitored on an oscilloscope, stored on magnetic tape and analyzed using a medical computer for constructing post-stimulus time histograms and dot raster displays.

Repetitive electrical stimuli were delivered through bipolar electrodes in the excitatory receptive fields (2ms duration at double the $\mathrm{C}$ fiber threshold, $0.33 \mathrm{~Hz}$ ) (Fig. 1B). Reproducible evoked discharges were confirmed and these responses were used as controls. Various stimuli were then applied to the acupuncture point and neuronal activity was followed for at least 5 minutes. The number of spikes per 30 seconds was counted and compared to the control value. In this study, however, only $\mathrm{C}$-evoked discharges were compared on the noxious index due to our inability to discriminate between evoked discharge from $\mathrm{A} \beta$ and $\mathrm{A} \delta$ fibers.

\section{Procedure for stimulation of the acupuncture point}

The analgesic effects of manual acupuncture and noxious pinching were compared. In the manual acupuncture application procedure, a needle $(\phi 0.32 \mathrm{~mm}, 25 \mathrm{~mm})$ was first inserted into ST 36 Zusanli to a depth of about $0.5 \mathrm{~cm}$ (Fig. 1C) and then retained for several seconds before manipulation. The entire procedure was completed within 30 seconds and termed the "retaining needle" period. Manual acupuncture was then performed for 30 seconds: the needle was lifted, thrust and rotated in a clockwise and counterclockwise manner at approximately $1 \mathrm{~Hz}$. The needle was then removed immediately after this 30 -second period of manual acupuncture. The entire manual acupuncture procedure was performed by a licensed acupuncturist. In the rat, the acupuncture point equivalent to the point in humans was determined purely on an anatomical basis. Instead of manual acupuncture, a noxious pinch was applied with serrated forceps to the lower parts of the body surface, such as hind paws and tail (Fig. 1D).

Different structures in ST 36 Zusanli were stimulated selectively by applying a needle to the skin, skin plus muscle (general procedure) and muscle (Fig. 1C, I-III). In the same neurons, each stimulus was consecutively employed after recovery of the C-evoked discharges. Muscle was stimulated by sectioning the skin at the acupuncture point after intradermic injection of procaine to allow direct insertion of the needle into the muscle.

The effects of intramuscular injections of $0.9 \%$ and $4.5 \% \mathrm{NaCl}(0.15 \mathrm{ml})$ to ST $36 \mathrm{Zusanli}$ were compared with that of manual acupuncture (Fig. 1E). Manual acupuncture was applied first followed by injection of $0.9 \%$ and $4.5 \% \mathrm{NaCl}$ consecutively after recovery of $\mathrm{C}$-evoked discharges in the 


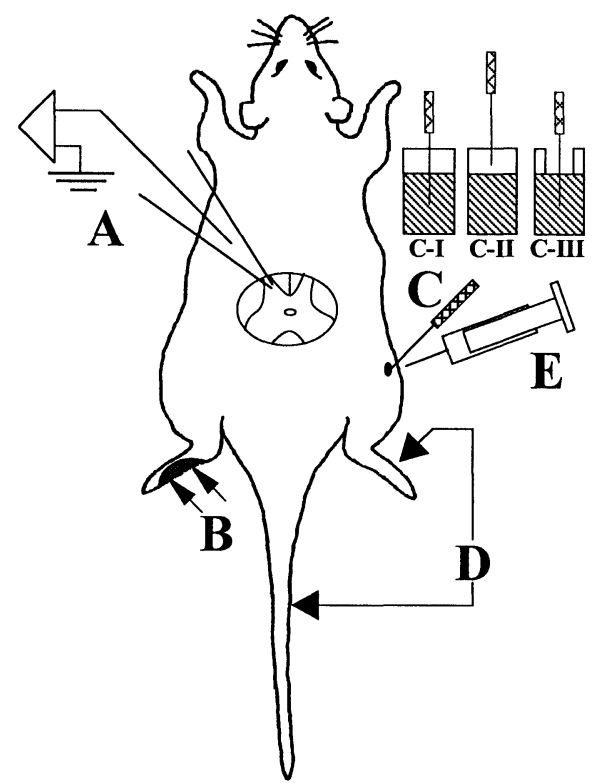

Fig. 1

Experimental design. A: extracellular unitary recordings were made from lumbar cord. B: repetitive electrical test stimuli were delivered through bipolar electrodes in excitatory receptive fields $(2 \mathrm{~ms}, 0.33 \mathrm{~Hz}, 2 \times \mathrm{CT})$. C: manual acupuncture applied to ST 36 Zusanli for stimulating skin plus muscle (C-I), skin only (C-II) and muscle only (C-III). D: noxious pinch stimuli applied to either hind paw or middle of tail. E: 0.9 or $4.5 \% \mathrm{NaCl}$ was injected into muscle of ST 36 Zusanli.

same neuron. Before injection, the injection needle was simply inserted into the muscle for several seconds prior to injection of the solutions in order to allow comparison with the effect of the "retaining needle" period in manual acupuncture.

At the end of each session, the recording sites were marked by iontophoresis using pontamine sky blue. The spinal cord was perfused with physiological saline followed by formalin solution (10\%) and then excised and fixed in formalin. Samples were frozen, cut in serial sections of $50 \mu \mathrm{m}$ and stained with cresyl violet.

\section{Results}

\section{Characteristics of neurons}

The effects of manual acupuncture in various forms and intramuscular injections of $4.5 \% \mathrm{NaCl}$ were studied in $25 \mathrm{WDR}$ neurons in a dorsal horn at the 5th lumbar level. The recording sites of 24 neurons were histologically identified by successful marking with pontamine sky blue (Fig. 2). These neurons responded to innocuous stimuli and increased their firing rate as the mechanical stimulus intensity was increased into the noxious range, and all received both $\mathrm{A}$ and $\mathrm{C}$ fiber inputs. Their receptive fields were always located ipsilateral to the recording sites and most of them (21/ 25) were small and were restricted to the planter region while the rest expanded to the lumbar region. Manual acupuncture vs. noxious pinch

The inhibitory effect of manual acupuncture on C-evoked discharges was studied in 9 neurons. 


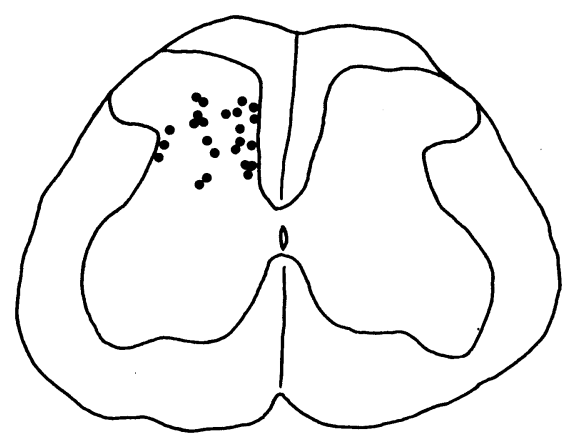

Fig. 2

Recording site of WDR neurons at 5th lumbar level.

As shown in Fig. 3A, the application of manual acupuncture resulted in two types of inhibition. One was a short-term, relatively weak effect elicited on C-evoked discharges in 7 neurons that lasted only for one minute following manual acupuncture. However, 3 of the 7 neurons showed a gradual reduction in the number of evoked discharges following this short-term inhibition. The other type of inhibition was long-lasting and pronounced, and was observed in 2 neurons. It is noteworthy that this strong inhibitory effect was elicited in a retaining needle period in one neuron when the needle had just been inserted through the skin into the muscle, and manipulation had not yet been performed.

Noxious pinches were applied to the skin of either the hind paw or tail for 6 neurons. These also inhibited C-evoked discharges from WDR neurons, and also exhibited both short-term and longlasting inhibition in 4 and 2 neurons, respectively (Fig. 3B). One neuron that exhibited relatively weak short-term inhibition showed a marked reduction in firing rate at 2.5 minutes. In general, the magnitude and time course of inhibition was very similar to that seen in manual acupuncture (Fig. 3A).

Selective stimulation of different structures at the acupuncture point

Manual acupuncture was consecutively performed on the skin, skin plus muscle and muscle at the acupuncture point and C-evoked discharges from WDR neurons were compared at 6 recording sites. As shown in Fig. 4, even though some neurons showed a slight reduction in C-evoked discharges, manual acupuncture performed only to the skin (Fig. 4A) was generally less effective than stimulation to the structures underlying the skin (Fig. 4B and C). These results are clearly apparent in the dot raster displays in Fig. 5. Manual acupuncture to the skin produced almost no effect on C-evoked discharges (Fig. 5A) while stimulation to the skin plus muscle produced a 3-minute inhibition starting at 30 seconds after application of manual acupuncture (Fig. 5B). Likewise, stimulation of muscle only produced even stronger, longer-lasting inhibition than that of the skin plus muscle (Fig. 5C).

Manual acupuncture vs. intramuscular injection of hypertonic $\mathrm{NaCl}$

The inhibitory effect of manual acupuncture was compared in 6 neurons with that of intramuscular injections of $0.9 \%$ and of $4.5 \% \mathrm{NaCl}$ (Fig. 6). The inhibitory effect of manual acupuncture (Fig. $6 \mathrm{~A}$ ) was similar to that described earlier in Figs. 3A and 4B. Intramuscular injection of $0.9 \% \mathrm{NaCl}$ had no effect on $\mathrm{C}$-evoked discharges with the exception of one neuron that showed a slightly reduced 

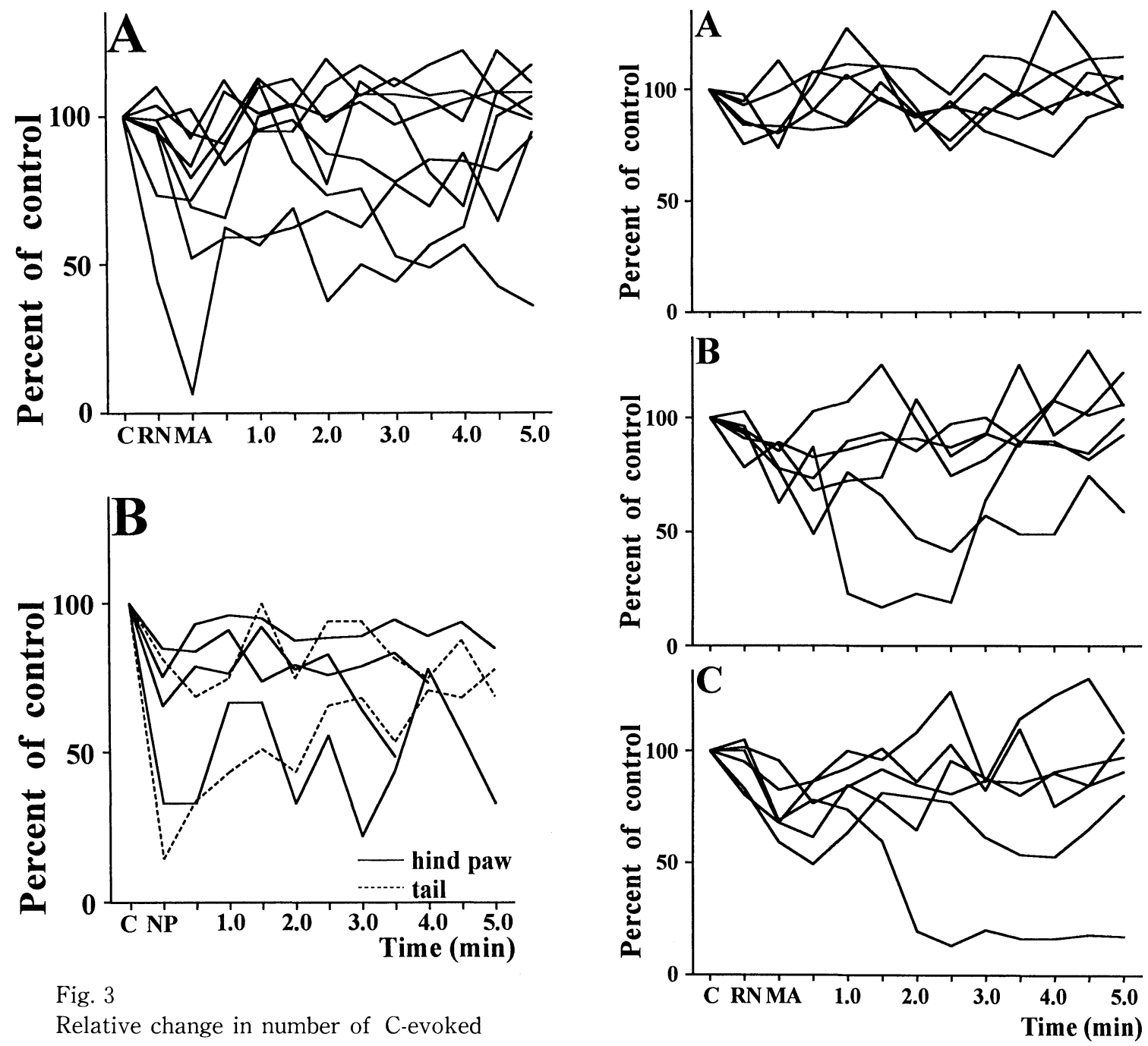

Relative change in number of $\mathrm{C}$-evoked discharges in spinal WDR neurons after conditioning stimuli compared to control value (C). A: manual acupuncture to ST 36 Zusanli (RN, retaining needle; MA, manual acupuncture). B: noxious pinch stimuli were applied to hindpaw or tail (NP, noxious pinch).

Fig. 4

Effects of selective stimulation by manual acupuncture to different structures of ST 36 Zusanli. Manual acupuncture to skin only (A), skin plus muscle (B) and muscle only (C).

number of spikes during the period in which the needle was inserted (Fig. 6B). On the other hand, intramuscular injection of $4.5 \% \mathrm{NaCl}$ resulted in dynamic suppression of C-evoked discharges, manily in the period of 30 seconds after injection, and the magnitude of inhibition was much stronger than that of manual acupuncture, although the time course of inhibition was generally the same (Fig. 6C). In fact, one neuron which showed short-term and weak inhibition with manual acupuncture was strongly inhibited by intramuscular injection of $4.5 \% \mathrm{NaCl}$, although the time course of inhibition was very similar to that of manual acupuncture. 
A

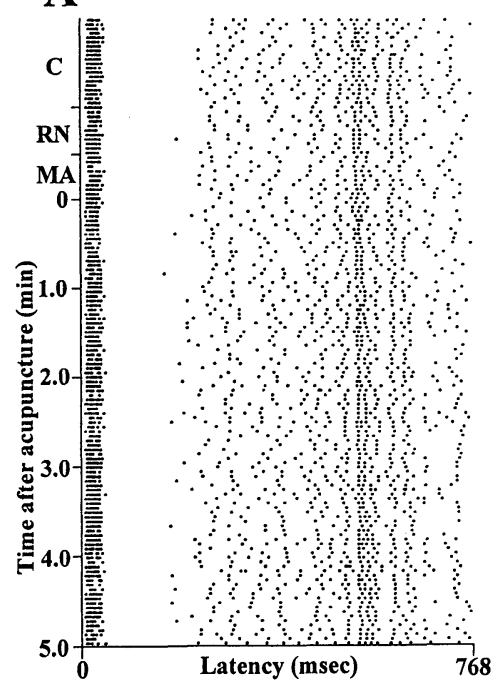

B

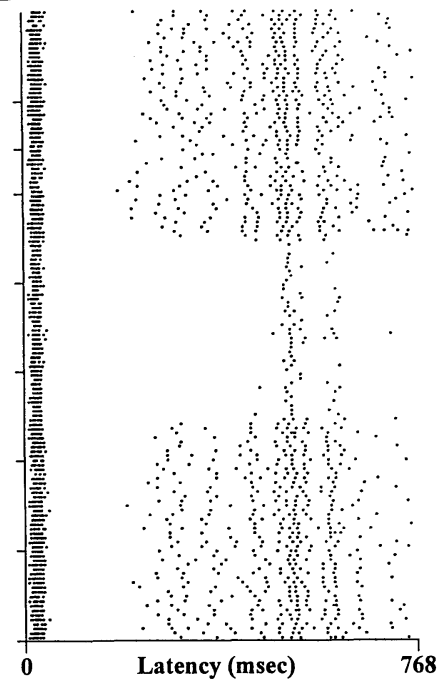

C

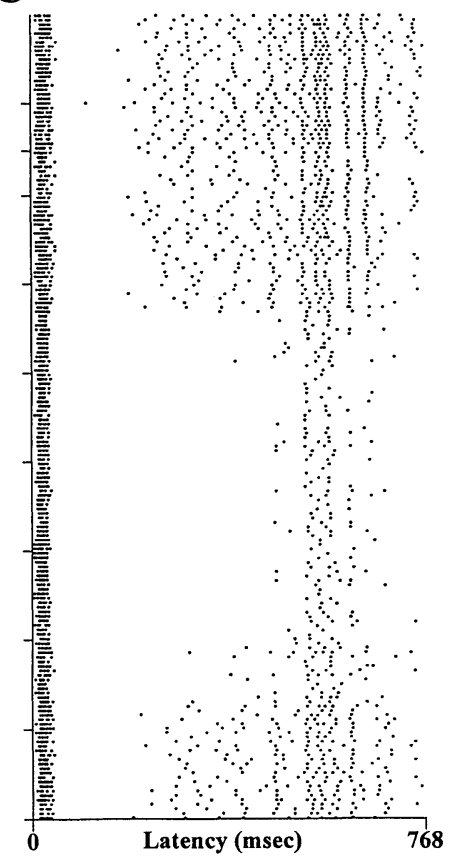

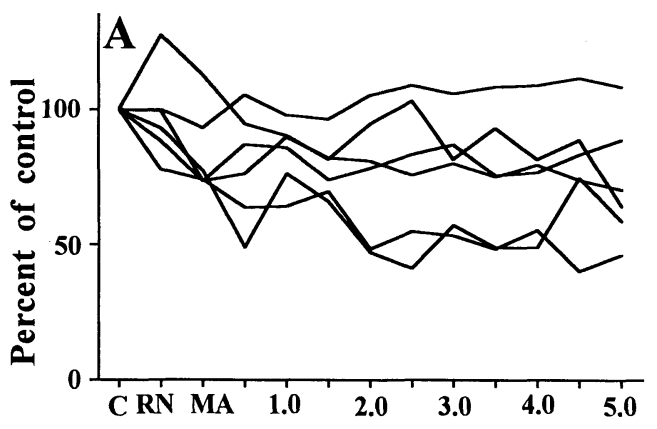
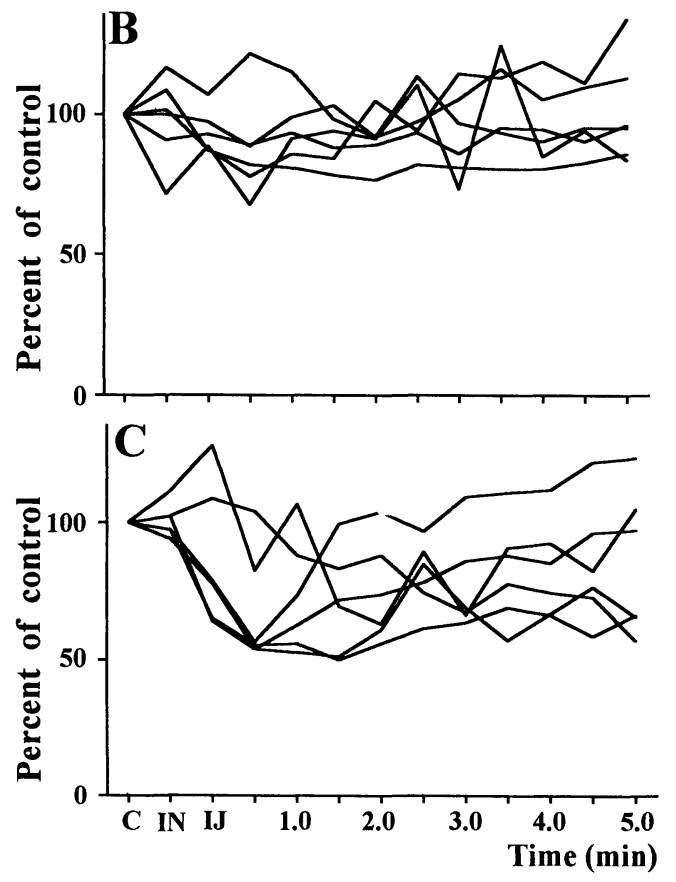

Fig. 5

Example from Fig. 4 showing dot raster displays. Manual acupuncture to skin only (A), skin plus muscle (B) and muscle only (C).
Fig. 6

Comparison of inhibitory effects on spinal WDR neurons. Manual acupuncture (A), $0.9 \% \mathrm{NaCl}(\mathrm{B})$ and $4.5 \% \mathrm{NaCl}(\mathrm{C}) . \quad \mathrm{IN}$ : insertion of injection needle, IJ: injection of solution. 


\section{Discussion}

In the present study, manual acupuncture and noxious pinches produced very similar inhibitory effects on C-evoked discharges in WDR neurons in the dorsal horn. These effects included both long-lasting, strong inhibition and short-term, relatively weak inhibition. The long-lasting inhibitory effect elicited by distal noxious pinches was previously reported and referred to as DNIC ${ }^{13)}$. Such an inhibitory process was in fact activated by all kinds of noxious stimuli and both supraspinal structures and an opioidergic link were shown to be involved. Using trigeminal convergent neurons, Bing et al. ${ }^{7}$ demonstrated that the inhibitory effects of manual acupuncture and DNIC showed various similarities. They concluded that manual acupuncture and DNIC shared a common inhibitory process, and that manual acupuncture should therefore be considered as a noxious stimulus. Moreover, Aikawa et al. $^{14)}$ and Kawakita ${ }^{15)}$ suggested that the main ascending pathway for impulses resulting from acupuncture stimulation traveled through the anterolateral fasciculus of the spinal cord where afferents conducted pain to the central nervous system.

As far as a short-term inhibition is concerned, Cadden et al. ${ }^{16)}$ reported that propriospinal pain modulatory processes triggered by noxious stimulation acted on convergent neurons in spinal animals. Hashimoto et al. ${ }^{8}$ previously demonstrated that needle manipulation induced a short-term, relatively weak inhibition in spinal WDR neurons. A recent study suggests that this inhibition still exists after transection of the upper level of the spinal cord ${ }^{17)}$.

Other studies demonstrated that needle manipulations activated neurons in the subnucleus reticularis dorsalis ${ }^{18)}$ and nucleus submedius ${ }^{19)}$ which responded exclusively to noxious stimuli. These results provided evidence that the needle sensation, at least in part, occupies pathways in common with pain sensation and activates not only supraspinal pain modulatory processes but also segmental or propriospinal ones.

Additionally, along with these two types of inhibition, a sharp decline in the number of evoked discharges followd by short-term inhibition was observed in several neurons. This effect seems to be a combination of short-term and long-lasting inhibition. As shown in Fig. 5B, long-lasting strong inhibition started approximately 30 seconds after application of manual acupuncture. This phenomenon and the steep decline in the number of evoked discharges after short-term inhibition almost coincided, in terms of a delay, with the onset of the long-lasting inhibitory effect.

We demonstrated that the inhibitory effect of manual acupuncture varied depending on the tissues stimulated at the acupuncture point. Although it should be emphasized that the possible involvement of other deep tissues such as fasciae, tendons and blood vessels in the muscle can not be ruled out in the current experimental design, it was obvious that stimulation of the muscle was essential for the induction of analgesic effects. Other studies also pointed out the importance of inputs from the muscle for producing analgesic effects. Andersson ${ }^{4)}$ described that the induction of analgesic effects by electroacupuncture should be accompanied by forceful muscle contractions and strong beating sensations, and activity in deep afferents were therefore an important feature in the pain-blocking mechanism during sensory stimulation in human subjects. Wall and Woolf $f^{20)}$ demonstrated that prolonged increases in the excitability of the flexion reflex in the rat were produced by muscle rather than by cutaneous C-inputs. Morton et al. ${ }^{21)}$ reported that strong inhibitory effects on nociceptive neurons in the cat dorsal horn were produced by deep radial nerve stimulation rather than by cutaneous noxious stimuli. 
However, in this study it is interesting to note that noxious cutaneous stimuli successfully inhibited $\mathrm{C}$-evoked discharges from WDR neurons in the spinal cord while manual acupuncture to the skin failed to activate pain inhibitory processes. Other studies demonstrated strong inhibitory effects on spinal nociceptive neurons elicited by noxious cutaneous stimuli such as a noxious pinch or heat ${ }^{7,13)}$. It seems only reasonable to explain that the qualities of the pain sensations produced by these two stimuli are absolutely different when applied to the experimenter's skin. Noxious cutaneous pinch stimuli caused unpleasant and intolerable pain sensations while needle manipulations in the skin produced only a pricking pain. On the other hand, inserting a needle into the muscle and manipulating it manually produces heavy, dull and deep pain sensations that often radiate. These typical sensations are called $D e Q i$ and this is clinically regarded as an important factor in the production of the desired acupuncture effect ${ }^{22)}$. It has been suggested that increase in the activity of specific nociceptors up to a certain level is one of the crucial factors in producing analgesic effects, and that in manual acupuncture in particular, nociceptive inputs from the muscle play an important role in the activation of pain inhibitory processes.

A hypothetical mechanism consisting of a polymodal receptor for acupuncture and moxibustion was first proposed by Kumazawa ${ }^{12)}$. This receptor is a nociceptor and responds to mechanical, chemical and noxious heat stimuli. The present study demonstrated the inhibitory effect of the intramuscular injection of $4.5 \% \mathrm{NaCl}$ that acted as stimulant for this polymodal receptor. In a similar investigation, Kawakita ${ }^{23)}$ reported that tail flick latencies in rats increased not only after intramuscular injection of $4.5 \% \mathrm{NaCl}$ but also following mechanical stimulation in which the injection needle was retained in the muscle for 20 minutes. The inhibitory effect of $4.5 \% \mathrm{NaCl}$ was less effective than mechanical stimulation. In contrast, the inhibitory effect of an intramuscular injection of $4.5 \% \mathrm{NaCl}$ in the present study was much stronger than that of manual acupuncture. This difference may be attributed to the experimental design. In the present stydy, the period of stimulation in manual acupuncture was only 30 seconds and the needle diameter was smaller than that of the needle used for injection. As in Kawakita's. study ${ }^{23)}$ which used a 20 -minute period of mechanical stimulation, our study also showed a similar reduction in $\mathrm{C}$-evoked discharges during the period in which the acupuncture needle or injection needle was inserted into the muscle. Paintal ${ }^{24)}$ mentioned that needle insertion alone activated group III fibers in skeletal muscle. It is noteworthy that the majority of thin fibers from muscles conduct excitation from such polymodal receptors ${ }^{25}$.

In conclusion, continuous excitation of a large number of polymodal receptors in muscle and/or possibly in other structures underlying the skin might be a fundamental factor in producing analgesic effects in manual acupuncture. The resulting signals then travel partly along the pain sensory pathways and activate supraspinal, segmental and/or propriospinal pain inhibitory processes.

\section{References}

1) Aikawa, S.: Neurophysiology of acupuncture analgesia. Sogo Rehabili, 6: 783-798, 1978

2) Chang, H. -T.: Integrative action of thalamus in the process of acupuncture for analgesia. Sci. Sinica, 16: 25-60, 1973

3) Pomeranz, B.: Scientific basis of acupuncture. In Stuz, G. \& Pomeranz, B. (Eds.) Acupuncture Textbook and Atlas, Springer-Verlag, Berlin, 1-13, 1987 
4) Andersson, S. A.: Pain control by sensory stimulation. In J. J. Bonica et al. (Eds.) Advances in pain research and therapy, Vol. 3, Raven Press, New York, 569-585, 1979

5) Wang, J. Q., Mao, L. and Han, J. S.: Comparison of the antinociceptive effects induced by electroacupuncture and transcutaneous electrical nerve stimulation in the rat. Int. J. Neurosci., 65: 117-129, 1992

6) Pomeranz, B. and Cheng, R.: Acupuncture reduces electrophysiological and behavioral responses to noxious stimuli: pituitary is implicated. Exp. Neurol., 54: 172-178, 1977

7) Bing, Z., Villanueva, L. and Le Bars, D.: Acupuncture and diffuse noxious inhibitory controls: naloxonereversible depression of activities of trigeminal convergent neurons. Neurosci., 37: 809-818, 1990

8) Hashimoto, T., Akita, H. and Aikawa, S.: Analgesia induced by manual acupuncture: its potency and implication. Kitasato Arc. Exp. Med., 65, Supple., 73-82, 1993

9) Kawakita, K.: Suppression of the jaw-opening reflex by conditioning A delta fiber stimulation and electroacupuncture in the rat. Exp. Neurol., 78: 461-465, 1982

10) Toda, K.: Effects of electro-acupuncture on rat jaw opening reflex elicited by tooth pulp stimulation. Jap. J. Physiol., 28: 485-497, 1978

11) Kawakita, K.: Role of polymodal receptors in the peripheral mechanisms of acupuncture and moxibustion stimulation. Pro. 2nd Con. Asian Ocean. Physiol. Soci., New Delhi, 731-739, 1990

12) Kumazawa, T.: Nociceptors and autonomic nervous control. Asian Med. J. 24: 632-656, 1981

13) Le Bars, D., Dickenson, A. H. and Besson J. -M.: Diffuse noxious inhibitory controls (DNIC). I. Effects on dorsal horn convergent neurons in the rat. Pain, 6: 283-304, 1979

14) Aikawa, S., Noda, K., Akita, H., Hotsumi, K., Ogata, M. and Hamanaka, S.: Physiological studies of ascending inhibitory pathway by acupuncture. Bul. Seisin-Igaku Institute, 24: 51-54, 1987

15) Kawakita, K.: The spinal ascending pathway of the afferent impulses responsible for the induction of acupuncture analgesia. Bul. Meiji Coll. Orient. Med., 1: 95-103, 1985

16) Cadden, S. W., Villanueva, L., Chitour, D. and Le Bars, D.: Depression of activities of dorsal horn convergent neurons by propriospinal mechanisms triggered by noxious inputs; comparison with diffuse noxious inhibitory controls (DNIC). Brain Res., 275: 1-11, 1983

17) Hashimoto, T., Aikawa, S.: Effects of manual acupuncture on spinal nociceptive neurons. Abst. of the third world conference on acupuncture, Kyoto, 120, 1993

18) Bing, Z., Villanueva, L. and Le Bars, D.: Acupuncture-evoked responses of subnucleus reticularis neurons in the rat medulla. Neurosci., 44: 693-703, 1991

19) Kawakita, K., Kanamori, S., Nakazono, Y. and Miura, T.: Responses of nociceptive medial thalamic neurons in the rat. Bul. Meiji Coll. Orient. Med., 5: 35-41, 1989

20) Wall, P. D. and Woolf, C. J.: Muscle but not cutaneous C-afferent input produces prolonged increases in the excitability of the flexion reflex in the rat. J. Physiol., 356: 443-458, 1984

21) Morton, C. R., Du, H. -J., Xiao, H. -M., Maisch, B. and Zimmermann, M.: Inhibition of nociceptive responses of lumbar dorsal horn neurons by remote noxious afferent stimulation in the cat. Pain, 34: 75-83, 1988

22) Technique of acupuncture and moxibustion. In an outline of Chinese acupuncture, The academy of traditional Chinese medicine (Ed.), Foreign languages press, Peking, 15-16, 1975

23) Kawakita, K.: Role of the polymodal receptors in acupuncture analgesia of the rat. Com. Med. East and West, 6: 312-321, 1982

24) Paintal, A. S.: Functional analysis of group III afferent fibers of mammalian muscles J. Physiol., 152: 250-270, 1960

25) Kumazawa, T. and Mizumura, K.: Thin-fibre receptors responding to mechanical, chemical, and thermal stimulation in the skeletal muscle of the dog. J. Physiol., 273: 179-194, 1977

Department of Physiology, School of Hygienic Sciences, Kitasato University, 1-15-1 Kitasato, Sagamihara, Kanagawa, Japan, 228. 